\title{
Effect of Cryogrinding on Chemical Stability of the Sparingly Water-Soluble Drug Furosemide
}

Karolina Adrjanowicz $\cdot$ Kamil Kaminski $\cdot$ Katarzyna Grzybowska $\cdot$ Lukasz Hawelek•Marian Paluch •Irena Gruszka $\cdot$ Daniel Zakowiecki • Wieslaw Sawicki • Przemyslaw Lepek • Wojciech Kamysz • Lukasz Guzik

Received: 18 November 2010 / Accepted: 27 May 2011 / Published online: 25 June 2011

(C) The Author(s) 2011. This article is published with open access at Springerlink.com

\begin{abstract}
Purpose To investigate the effect of cryogrinding on chemical stability of the diuretic agent furosemide and its mixtures with selected excipients.

Methods Furosemide was ground at liquid nitrogen temperature for 30, 60, 120 and 180 min. Mixtures of furosemide-PVP and furosemide-inulin $(1: 1)$ were milled under cryogenic conditions. Materials were analyzed by XRD, UPLC, MS and NMR. Results Upon increasing the milling time, a significant build-up of an unidentified impurity I, probably the main degradation product, was noticed. Cogrinding of furosemide with PVP and inulin worsened chemical stabilization of the pharmaceutical. The main degradation product formed upon cryomilling was subsequently identified as 4-chloro-5-sulfamoylanthranilic acid (CSA). Based on some theoretical considerations involving specific milling conditions, the milling intensity and an expected specific milling dose have been calculated. Results indicate that cryogenic grinding is capable to initiate mechanically induced decomposition of furosemide.
\end{abstract}

K. Adrjanowicz $\cdot$ K. Kaminski • K. Grzybowska $\cdot$ L. Hawelek • M. Paluch Department of Biophysics and Molecular Physics, Institute of Physics University of Silesia

ul. Uniwersytecka 4

40-007 Katowice, Poland

I. Gruszka

Department of Experimental Physics, Institute of Physics

University of Silesia

ul. Uniwersytecka 4

40-007 Katowice, Poland

D. Zakowiecki

Preformulation Department R\&D

Pharmaceutical Works Polpharma SA

Pelplinska 19

83-200 Starogard Gdanski, Poland
Conclusions Cryogenic grinding can activate and accelerate not only structural changes (solid state amorphization) but also chemical decomposition of pharmaceuticals. A cryogenic milling device should be considered as a chemical reactor, where under favourable conditions chemical reactions could be mechanically initiated.

KEY WORDS amorphous pharmaceuticals · cryogenic grinding · furosemide $\cdot$ mechnochemical reactions $\cdot$ solid state amorphization

\section{INTRODUCTION}

According to Biopharmaceutical Classification System (BCS), pharmaceutically important particles are divided into four categories on the basis of aqueous solubility and permeability via oral route of delivery (1). Because of low solubility and permeability, Active Pharmaceutical Ingre-

\footnotetext{
W. Sawicki P. Lepek

Department of Physical Chemistry

Medical University of Gdansk

Hallera 107

80-4I 6 Gdansk, Poland

W. Kamysz • L. Guzik

Department of Inorganic Chemistry

Medical University of Gdansk

Hallera 107

80-416 Gdansk, Poland

K. Adrjanowicz ( $\triangle)$

Institute of Physics, University of Silesia

ul. Uniwersytecka 4

40-007 Katowice, Poland

e-mail:kadrjano@us.edu.pl
} 
dients (APIs) belonging to the last category (i.e. IV class) are likely to exhibit low bioavailability and are still the most challenging molecules for the modern pharmaceutical industry. One of the most promising ways to tackle the problem of insufficient dissolution rate of poorly watersoluble drugs is particle size reduction. As shown in the literature, micronization generally leads to improvement of dissolution properties of drugs through increase in surface area of micro- or nano-substances (2). A variety of methods are used for producing drugs with reduced particle size. However, micronization of drugs is frequently attempted through extended mechanical milling.

Mechanical treatment of crystalline solids in a mill (known also as grinding) is a very popular technique applied in many fields of industry to reduce particle size. The large amount of mechanical perturbations generated during milling may result in significant changes in the structure of the grinded material, including polymorphic transformations, crystal defects and partial or complete amorphization $(3,4)$. In the latter case, complete transformation from crystal to amorphous state occurs only if the grinding process takes place at a temperature much lower than the glass transition temperature, $\mathrm{T}_{\mathrm{g}}$, of an equivalent supercooled liquid.

Amorphous drugs offer a very interesting perspective for pharmacy, basically because they are markedly more soluble and dissolve faster as compared to their crystalline counterparts (5). Nevertheless, one should still remember that an amorphous solid is in the state of non-equilibrium and sooner or later will revert to a more stable crystalline state (6). Moreover, many studies have revealed that enhanced chemical reactivity of amorphous pharmaceuticals related to molecular mobility speeds up their chemical degradation (7).

Solid state amorphization via grinding has extensively been studied for a long time. This research is concerned mainly with metallic systems and inorganic compounds (8). However, in recent years a lot of effort has been taken by the Decamps group to put some insight into crystal-glass transformation induced by milling in organic materials, especially in the food and pharmaceuticals areas (9-11).

It is generally claimed that physical stability of amorphous drugs prepared by grinding of crystalline solids is reduced as compared to that obtained by quenching of liquid. For instance, glassy state of indomethacin obtained by very slow cooling of the liquid is stable against crystallization for over 2 years (12), but amorphous state of IMC obtained by grinding is less stable and recrystallizes to $90 \%$ after approximately $13-15 \mathrm{~h}$ (13). Certainly, the changes which appear during grinding can affect the stability and other physical properties of outcome material. Thus, a better understanding of the nature of the crystal-toamorphous transformation seems to be fundamental.
In the literature there are several concepts for elucidation of the crystalline-amorphous state transformation induced by milling. For example, it has been suggested that during mechanical impact, a certain amount of mechanical energy is liberated. This can cause a local heating effect resulting in local melting of the sample followed by fast quenching. However, as demonstrated a few years ago, no significant increase in temperature upon milling occurred $(10,11)$. The next scenario is based on the Lindemann melting criterion stating that the crystallineamorphous solid transformation can simply be explained in terms of melting of critically disordered crystals at temperatures below the glass transition point where the supercooled liquid exists in a configurationally-frozen state (glassy state) (14). On the other hand, some researchers have suggested that the solid-state amorphization occurs as the result of softening of the crystalline lattice vibrations, leading in a consequence to its collapse, while others claim that during milling progressive lattice defects give rise to the energy of the system. This provides essential thermodynamic-driven force to begin transformation (15). It is also worth keeping in mind that in the Martin and Bellon's 'driven material concept' approach, the whole transformation involves competition between thermally independent disordering process induced by milling and thermally depending restoration process (16).

Grinding, as a non-conventional way of amorphization, is a great alternative for the commonly used supercooling of the molten crystal. This method is especially important with compounds undergoing thermal degradation at the melting point. It is thus impossible to prepare amorphous state by quenching a liquid. It is also very suitable when a material has a strong sensitivity to solvents and consequently there is a big problem associated with selection of the solvent for the freeze- and spray-drying technique, or when it is necessary to prepare a pure amorphous API without additional excipients, not dispersed molecularly in any polymeric matrix.

Grinding of various types of crystalline materials can be carried out using two options: 1) at room temperature in a traditional ball mill or 2) in a cryogenic impact mill immersed in liquid nitrogen (so-called cryogrinding, cryomilling). Recently, cryogrinding of pharmaceuticals has attracted much attention $(13,17,18)$. As it turns out, this method is more efficient to prepare the glassy drugs than the ball milling, since the material is completely frozen during grinding. It is also believed that chemical degradation does not occur in this case, because the liquid nitrogen temperature should prevent local temperature warm-up. It is worth noting that until now there have been no precise studies concerning drug decomposition upon cryomilling. A few years ago, Graeser et al. reported on a lowered chemical stability of simvastatin during cryomilling; however, the 
authors suggested that this effect was related to the preparation method rather than to degradation (19).

The aim of this study is to examine the effect of cryogrinding on the physical and chemical stability of the popular diuretic agent, furosemide. The crystalline furosemide is sparingly soluble in aqueous systems, especially the acidic ones. Experimental water solubility of crystalline furosemide $(0.006 \mathrm{mg} / \mathrm{mL}(20))$ as well as its bioavailability $(20-60 \%(21))$ allow for classifying the drug as a class IV compound in BCS. From the literature it is also known that furosemide appears to be very unstable at lower $\mathrm{pHs}$ and undergoes hydrolysis and photochemical degradation in aqueous solution (22). Moreover, it decomposes at a melting point $\left(\mathrm{T}_{\mathrm{m}}=206^{\circ} \mathrm{C}\right)$ (23). Consequently, it is impossible to prepare its amorphous form in a conventional way. For this reason, furosemide appeared to be one of the challenging molecules for pharmaceuticals researchers. In the past, some attempts had been made to improve its stability in aqueous systems as well as its dissolution profile $(24,25)$. For example, a remarkable enhancement of the dissolution rate was reported for a solid dispersion of furosemide-PVP (26) or for ball milling of furosemide with crospovidone (27). Interestingly, previous researchers didn't report about any signs of degradation of the drug caused by milling.

In this study, we have tested the effect of cryogrinding of pure furosemide on its stability. The samples cryomilled for 30, 60, 120 and 180 min were then analyzed with the use of several techniques, namely X-Ray Powder Diffraction (XRD), Mass Spectrometry (MS), Nuclear Magnetic Resonance (NMR) and Ultra-Performance Liquid Chromatography (UPLC). The latter is known to be the most sensitive analytical method, allowing detection of any trace impurity. As will be shown in this paper, the milling of furosemide in liquid nitrogen is actually not such a safe method of solidstate amorphization as expected. Briefly, our result leads to the conclusion that during cryomilling (milling carried out at a liquid nitrogen temperature) chemical degradation of furosemide induced by mechanical treatment occurs. For this reason, it seems that the effect of cryomilling on the physicochemical properties of APIs ought to be more carefully studied.

\section{MATERIALS AND METHODS}

\section{Materials}

Furosemide (4-chloro-2-(furan-2-ylmethylamino)-5sulfamoylbenzoic acid, $\mathrm{G}_{12} \mathrm{H}_{11} \mathrm{ClN}_{2} \mathrm{O}_{5} \mathrm{~S}$, is a white crystalline powder. It was supplied by the Polpharma Pharmaceutical Works Poland and used without further purification. The purity of the drug was declared by supplier as being greater than $99 \%$. The chemical structure of the drug is shown in the inset in Fig. 1. For cogrinding, polyvinylpyrrolidone (PVP) K30 (average molecular weight 40,000 ) and inulin (purity 99\%) were used. Both materials were supplied by the Polpharma Pharmaceutical Works Poland.

\section{Preparation Technique-Cryogrinding of the Crystalline Material}

The grinding was performed using a cryogenic impact mill (6750 freezer/mill SPEX CertiPrep, Inc., USA) consisting of a stainless steel vessel immersed in liquid nitrogen, within which a stainless steel rod was vibrated by means of magnetic coil. Before grinding, a 10-min precooling time was programmed. Then, the mill was set at an impact frequency of 15 cycles per second for 6-min grinding periods separated by 3-min cool-down periods. The mass of each sample was $1 \mathrm{~g}$. Total milling times of furosemide were 30,60, 120 and $180 \mathrm{~min}$. The powdered mixtures of furosemide-PVP and furosemide-inulin were prepared at 1:1 mass ratios and cryomilled for $60 \mathrm{~min}$.

After milling, the grinding vial was transferred to a vacuum oven and allowed to warm to room temperature. The freshly prepared cryomilled furosemide is a grey powder with a slightly brown hue, intensified upon increasing the milling time. Both furosemide-PVP and furosemide-inulin mixtures after 60 min of cryomilling are yellow powders. Expected humidity of the cryomilled

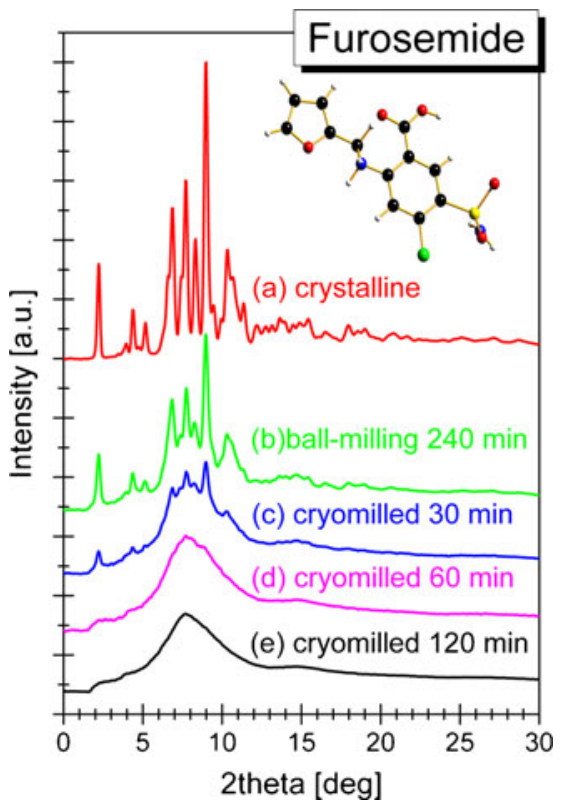

Fig. I Powder $x$-ray diffraction patterns (XRDP) starting from crystalline furosemide (a), furosemide after 240-milling in a traditional ball mill (pattern b) and after cryogrinding for 30,60 and 120 min (respectively, patterns $\mathbf{c}-\mathbf{e})$. 
samples was less than 4\%. The ICP-AES analysis showed that the iron content of a sample cryomilled for $180 \mathrm{~min}$ sample was at a level matching that of a tap water. The ground samples prepared in such a way were then analyzed by the methods indicated below.

For the ball milling of furosemide at ambient temperature, a Planetary Ball Mill (Retsch) was used. A zirconium jar was filled with $10 \mathrm{~g}$ of furosemide, and 6 balls $(20 \mathrm{~mm}$ in diameter) of the same material were added. The rotation speed of $400 \mathrm{rpm}$ was set. Each milling cycle lasted 15 min and was followed by a 5 -min break. The total milling times were $240 \mathrm{~min}(4 \mathrm{~h})$ and $1440 \mathrm{~min}(24 \mathrm{~h})$.

\section{X-ray Diffraction (XRD)}

The X-ray diffraction experiment was performed at ambient temperature on a Rigaku-Denki D/MAX RAPID II-R diffractometr with a rotating anode $\mathrm{AgK}_{\alpha}$ tube $(\lambda=$ $0.5608 \AA)$, an incident beam (002) graphite monochromator and an image plate in the Debye-Scherrer geometry. The pixel size was $100 \times 100 \mu \mathrm{m}$. All samples were placed inside Lindemann glass capillaries ( $2 \mathrm{~mm}$ in diameter). Measurements were run with the sample filled and empty capillaries, and the intensity of the empty capillary was then subtracted. The beam width at the sample was $0.1 \mathrm{~mm}$. The two-dimensional diffraction patterns were converted into the one-dimensional intensity data using a suitable software.

\section{Differential Scanning Calorimetry (DSC)}

DSC measurements were carried out using a Perkin Elmer Pyris 1 DSC instrument (PerkinElmer Life And Analytical Sciences, Massachusetts, USA) with liquid nitrogen cooling. The instrument was calibrated for temperature and heat flow using high-purity standards of indium. The sample $(m=0.00756 \mathrm{~g})$ was placed in a sealed aluminium pan. The thermogram was collected during heating of amorphous furosemide prepared by cryomilling at a rate of $10^{\circ} \mathrm{C} / \mathrm{min}$ from $-20^{\circ} \mathrm{C}$ to $190^{\circ} \mathrm{C}$.

\section{Test of Purity of Cryomilled Furosemide and Chemical Stability in Solid State and Solutions}

\section{Ultra-Performance Liquid Chromatography (UPLC)}

For the analysis of Furosemide and its degradation products (impurities) a simple and sensitive chromatographic method has been developed. The same method was used for examination of the stability of the drug in the solid state and solutions.

The analyses were performed using the Waters Acquity UPLC system (Millford, MA, USA), equipped with a Binary Solvent Manager, Sample Manager, Column Manager, and Photodiode Array e $\lambda$ Detector. Data acquisition and evaluation were carried out using the Empower Pro 2 software (Waters, Millford, MA, USA). A summary of the chromatographic conditions is given in Table I. The LC separation was achieved within a run time of $10 \mathrm{~min}$.

\section{Separation and Detection of Main Degradation Product Formed During Cryomilling of Furosemide}

\section{High Performance Liquid Chromatography HPLC}

The analysis was performed on an HPLC Beckman Gold System (Beckman Coulter, Brea, CA, USA) instrument using a thermostatted $\left(30^{\circ} \mathrm{G}\right)$ Phenomenex $\mathrm{C}_{18}$ Luna column $(150 \times 4.6$ I.D. particle size $5 \mu \mathrm{m} ; 100 \AA)$. The eluate was monitored at $230 \mathrm{~nm}$. Total run time was $30 \mathrm{~min}$ with a flow rate of $0.5 \mathrm{ml} / \mathrm{min}$. Acetonitrile and acetic acid $(0.1 \%)$ were filtered through a $0.45 \mu \mathrm{m}$ membrane filter and used as a mobile phase. First, an isocratic flow (acetonitrile: acetic acid 20:80 v/v) was
Table I Chromatographic Conditions (UPLC)

\begin{tabular}{|c|c|}
\hline Column: & ACQUITY UPLC BEH $C_{18} 1.7 \mu \mathrm{m} 2.1 \times 150 \mathrm{~mm}$ (Waters, Wexford, Ireland) \\
\hline Mobile phase A: & $0.1 \%$ formic acid in water, $\mathrm{pH}$ adjusted to 5.6 with triethylamine \\
\hline Mobile phase B: & acetonitrile \\
\hline \multirow[t]{3}{*}{ Gradient program: } & start with $10 \%$ of mobile phase $B$ \\
\hline & at $9.0 \mathrm{~min} 50 \%$ of mobile phase $\mathrm{B}$ \\
\hline & at $10.0 \mathrm{~min} 70 \%$ of mobile phase $\mathrm{B}$ \\
\hline Flow rate: & $0.3 \mathrm{ml} / \mathrm{min}$ \\
\hline Column temp: & $30^{\circ} \mathrm{C}$ \\
\hline Injection volume: & $1.0 \mu \mathrm{l}$ \\
\hline Injection mode: & Partial Loop with Needle Overfill \\
\hline Detection wavelength: & $270 \mathrm{~nm}$ \\
\hline Data collection rate: & 40 points/s \\
\hline
\end{tabular}


applied. After 10 min the composition of the mobile phase was changed gradually up to $80 \%$ acetonitrile: $20 \%$ acetic acid, which was maintained for the last $10 \mathrm{~min}$.

\section{LC/MS Analysis}

LC/MS system consisted of an Agilent 1100 series LC system (Agilent Technologies, Santa Clara, CA, USA), interfaced with MS-Bruker Daltonics HCTultra with a turbo electrospray ionization detector (ESI). G18, Phenomenex $\mathrm{C}_{18}$ Luna column $(150 \times 4.6$ I.D. particle size $5 \mu \mathrm{m} ; 100 \AA)$ was used to determine sample degradation products. Furosemide samples were dissolved in acetonitrile, and the solution was introduced into the ESI source by continuous infusion using a syringe pump at a flow rate of $0.5 \mathrm{ml} / \mathrm{min}$. The ESI source was operated at $4 \mathrm{kV}$ (in positive and negative polarization), with the capillary heater at $350^{\circ} \mathrm{C}$ and sheath gas pressure of 30 psi. Mass spectra in the negative and positive ion modes were acquired over the range $\mathrm{m} / \mathrm{z}$ 50-500. The LC experiments were carried out in the same conditions as by HPLG method.

\section{Preparative Separation by High Performance Liquid Chromatography (HPLC)}

The separation was carried out with Kontron Instruments (Milan, Italy) using a thermostated $\left(25^{\circ} \mathrm{C}\right)$ Phenomenex $\mathrm{C}_{18}$ Columbus column $(250 \times 10.00$ I.D. particle size $5 \mu \mathrm{m} ; 100$ $\AA)$ to separate impurity from waste fractions. Detection wavelength was $230 \mathrm{~nm}$. The elution conditions were a linear gradient of acetonitrile and $0.1 \%$ trifluoroacetic acid (5-40\% of acetonitrile) in $60 \mathrm{~min}$ with a flow rate of $4.0 \mathrm{ml} / \mathrm{min}$. After $60 \mathrm{~min}$ the composition of the mobile phase was changed gradually up to $90 \%$ acetonitrile for the last $15 \mathrm{~min}$.

\section{Matrix Assisted Laser Desorption lonization-Time of Flight (MALDI-TOF-MS) MS Mass Spectrometry}

The MALDI-TOF mass spectra ware recorded on a Bruker Biflex III (MA, USA) instrument in a reflector mode. The ion source was set to $19.0 \mathrm{kV}$ with the lens and reflector voltage of $9.6 \mathrm{kV}$ and $20.0 \mathrm{kV}$, respectively. For the analysis, the DHB (2,5-dihydrobezoic acid) matrix was used. Laser excitation was at $337.1 \mathrm{~nm}$ with $27 \%$ attenuation.

\section{Proton Nuclear Magnetic Resonance ('H NMR) Spectroscopy}

The freeze-dried sample, collected after preparative separation by means of HPLC, was diluted in DMSO solvent. ${ }^{1} \mathrm{H}$ NMR spectrum was registered on a Varian Mercury
$400 \mathrm{MHz}$ spectrometer. The acquisition time and delay times were 2 and $1 \mathrm{~s}$, respectively.

\section{RESULTS AND DISCUSSION}

\section{Physical Characterization of Cryomilled Furosemide}

Figure 1a shows the X-ray diffraction pattern of the intact, non-milled furosemide, which was taken at room temperature and used as a reference. The sharp and highly intense Bragg's peaks confirmed crystalline nature of the drug. The diffraction patterns presented in Fig. 1c-e correspond respectively to the samples after 30,60 and $120 \mathrm{~min}$ of cryogrinding. In those samples, a strong reduction of crystallinity proceeds with increasing milling time, resulting in a considerable decrease of diffraction peaks. As illustrated in Fig. 1c, significant broadening and decrease of peak intensities appeared just after $30 \mathrm{~min}$ of cryomilling. For this sample, the degree of crystallinity (calculated as a ratio of X-ray diffraction peaks areas for partially crystalline sample to that being $100 \%$ crystalline) was found to be $12 \%$. After $60 \mathrm{~min}$ of cryomilling, furosemide becomes almost completely amorphous (degree of crystallinity $2 \%$ ). Complete conversion crystalline-amorphous furosemide was noticed after $70 \mathrm{~min}$ (data not shown). The diffraction patterns recorded at room temperature for samples cryomilled for 120 and $180 \mathrm{~min}$ revealed absence of Bragg's peaks, which were replaced by halo patterns (calculated degree of crystallinity $0 \%$ ), being a characteristic feature of materials having no long-range threedimensional molecular order, i.e amorphous one.

As frequently reported in the literature, transformation of a crystalline material to a completely disordered one caused by mechanical milling occurs only at temperatures much lower than the glass transition temperature, $\mathrm{T}_{\mathrm{g}}$, of corresponding supercooled liquid (11). This explains why the crystalline-amorphous powder transformation takes place more readily at a lower temperature. It is worth pointing out that the reduction of the milling temperature brings the same effect as the increase in milling intensity. Hence, by cryomilling it is possible to reduce time required for considerable particle size reduction and to avoid extremely long milling times to get the same effect as in a traditional ambient-temperature device. To illustrate the lower efficiency in production of amorphous materials by mechanical milling carried out at room temperature, the grinding process of FUR was also performed in a traditional ball mill (milling intensity $\Omega=$ $400 \mathrm{rpm})$. In Fig. 1b the XRD patterns of a sample ground for $240 \mathrm{~min}$ at ambient conditions are shown. Certainly, reduction of peak intensities indicating a decrease in grain size and distortion of crystalline lattice 
was observed (degree of crystallinity $31 \%$ ), but this effect is not as significant as in the case of milling carried out at liquid nitrogen temperature. This finding agrees with results reported for other systems like those of indomethacin or trehalose. For the former, amorphous state was reached only after $60 \mathrm{~min}$ of cryogrinding (13), while during mechanical treatment at room temperature more than $1200 \mathrm{~min}$ (9) are required to get a similar effect. Similarly, complete amorphization of trehalose in the traditional ball mill was reached even after $1380 \mathrm{~min}$ of grinding (10).

It should also be noted that Villiers and Tiedt (28) have found that prolonged milling of furosemide in a traditional ball mill resulted in a practical limit in particle size reduction within a relatively short time (30 min). Indeed, even after $1440 \mathrm{~min}$ of milling in the conventional device the degree of crystallinity was estimated to be greater than $25 \%$. Our results indicate that in the high-impact cryogenic device we are able to effectively reduce the particle size to a level probably hardly attainable during room temperature treatment.

As already mentioned in the Introduction, solid-state amorphization of pharmaceuticals is a very problematic issue, and several concepts were proposed. Some of them suggest that the process of amorphization occurring during mechanical treatment in a mill cannot be regarded as glass transition in the traditional sense (15). However, the presence of the glass transition event can be detected by monitoring the change of thermodynamic variables such as heat capacity. In Fig. 2 we present a DSC thermogram recorded upon heating $\left(10^{\circ} \mathrm{C} / \mathrm{min}\right)$ of a sample cryomilled for $180 \mathrm{~min}$. Within the examined temperature range, two thermal events were observed: the glass transition at $55^{\circ} \mathrm{C}$ (calculated as a midpoint of the glass transition step)

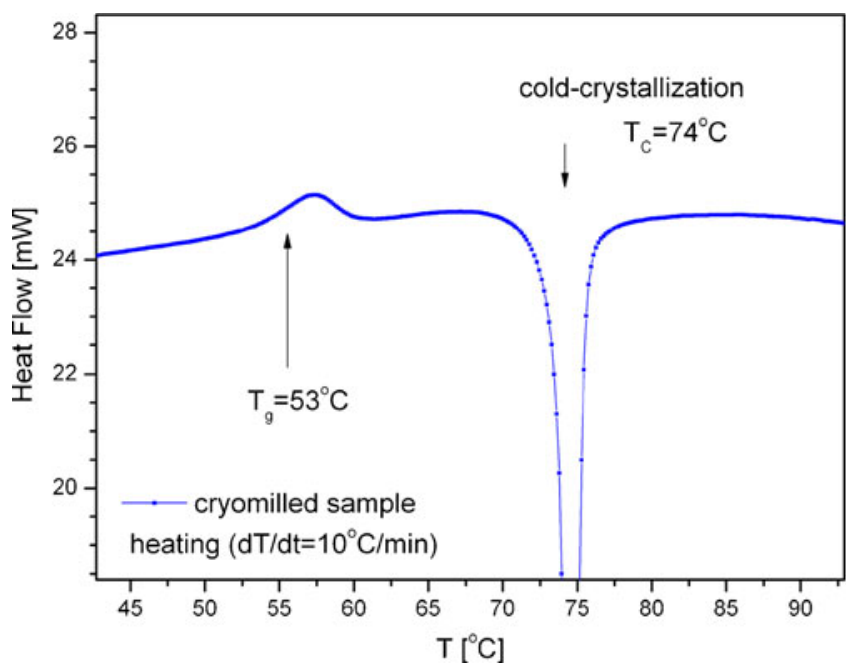

Fig. 2 DSC thermogram recorded upon heating $\left(10^{\circ} \mathrm{C} / \mathrm{min}\right)$ of furosemide cryomilled for $180 \mathrm{~min}$. followed by recrystallization at $74^{\circ} \mathrm{C}$. Thus, characteristic for the glass transition, jump in the heat capacity really occurred. This means that the drug can certainly reach the glassy state upon cryogrinding. The exothermic peak around $\mathrm{T}_{\mathrm{c}}=74^{\circ} \mathrm{C}$ was ascribed to recrystallization of the cryomilled sample. Such a thermal behavior is often observed in the case of ground samples.

Next, time-dependent XRD measurements at room temperature and 10\% RH were carried out to test physical stability of the amorphous furosemide prepared by cryomilling. In Fig. 3 we present diffraction patterns recorded at specified time intervals. As the storage time increases, initially amorphous furosemide tends towards a more stable crystalline form. This is visible as an increase in Bragg's peaks intensities. However, between 3 and 21 days of storage, the degree of crystallinity does not significantly increase and maintains at an almost constant value of $6 \%$. The slowing down of the crystallization progress is quite often observed with cryomilled samples. For example, when the degree of crystallinity of the initially amorphous cryomilled ziprasidone base and ziprasidone hydrochloride reached $30 \%$ and $37 \%$, respectively (that happened after 2 weeks of storage at room temperature), no significant changes in the crystallization progress were observed later on (29).

We claim that the degree of crystallinity remains constant at $6 \%$ because of our specific storage conditions. Crystallization of cryomilled furosemide was monitored after placing it into the Lindemann glass capillary of $2 \mathrm{~mm}$

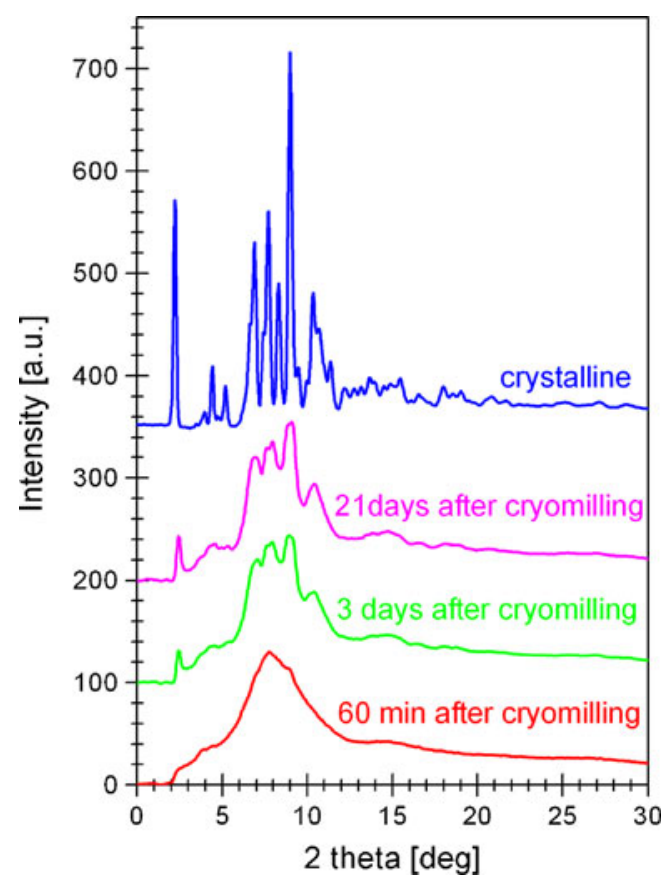

Fig. 3 Changes in the $X$-ray diffraction patterns of furosemide cryomilled for $60 \mathrm{~min}$ and stored at $25^{\circ} \mathrm{C}$ and $10 \% \mathrm{RH}$. 
in diameter. Throughout the whole study, cryomilled materials stayed in that capillary, with access to fresh air. We suppose that when different storage conditions were adopted during monitoring the degree of crystallinity, the stability of cryomilled furosemide might be completely different. For example, when the samples were exposed to greater $\mathrm{RH}$ conditions or we provided the greater free surface, the crystal growth might be orders of magnitude faster.

\section{Chemical Instability of Cryomilled Furosemide}

As mentioned in the Introduction, due to its poor solubility and bioavailability, crystalline furosemide is a challenging molecule for the pharmaceutical industry. Still more so, furosemide has been known to be unstable during adverse storage conditions. It undergoes acid-catalyzed hydrolysis in water solutions, photochemical degradation in the solid state and thermal decomposition at a melting point. In all three cases, the same degradation product is formed, namely 4-chloro-5-sulfamoylanthranilic acid (CSA) $(23,30)$. As reported, both furosemide and its main degradation product possess toxic potentials (31) and might undergo further photodechlorination to N-furfuryl-5-sulfamoylanthranilic acid (FSA) (32). For this reason, it seems that the crystalline furosemide itself is strongly susceptible to degradation when exposed to inappropriate storage or manufacture conditions.

The milling procedure of furosemide was carried out at liquid nitrogen temperature where, as suggested, no chemical degradation of the milled material should occur. Still more so, some of our previous studies concerning amorphous pharmaceuticals (like telmisartan or ziprasidone) formed by cryomilling have clearly demonstrated that the amount of impurities formed during that type of mechanical treatment varies (irrespective of the milling time) only from $0.2 \%$ to $0.5 \% \quad(29,33)$. This certainly implies that cryomilling seems to be a really safe method of solid-state amorphization.

To check whether this is also true for the drug under study, we used the ultra performance liquid chromatography (UPLG) technique, as an infallible tool in the purity analysis of active substances and their final dosage forms. A chromatogram of the crystalline furosemide used for further analysis as a reference is displayed in Fig. 4, as a black solid line. As seen, it consists of one very well-pronounced peak assigned to furosemide and the other, very small one with the relative retention time of 0.26 . The unknown impurity assigned to this peak was denominated as Imp.1. The area under the mother peak was found to be equal $99.95 \%$. After 30, 60, 120 and $180 \mathrm{~min}$ of effective cryomilling of the furosemide (1 g each time), next UPLC chromatograms

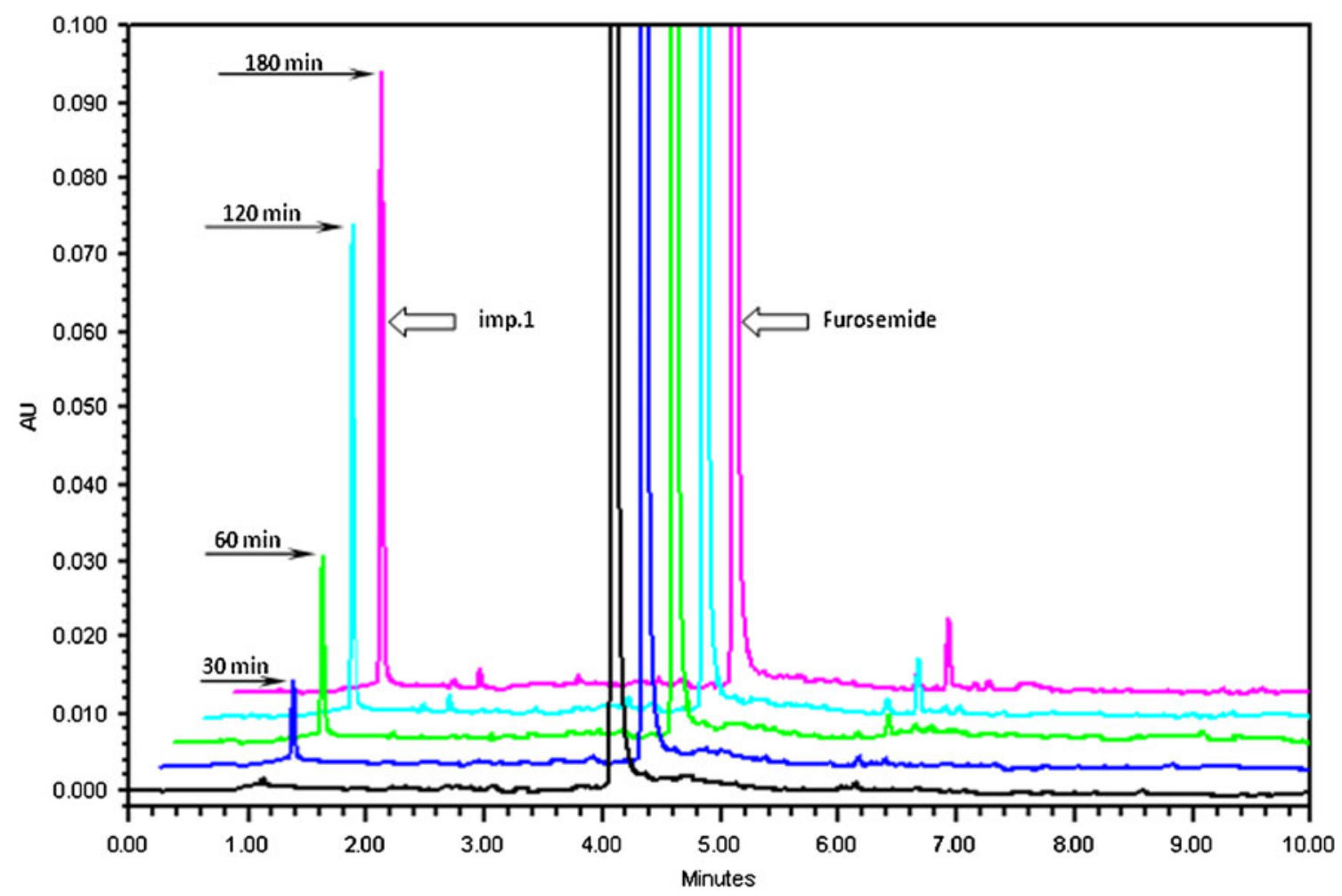

Fig. 4 Overlaid chromatograms of crystalline furosemide (black) and that cryomilled for $30 \mathrm{~min}$ (navy blue), $60 \mathrm{~min}$ (green), $120 \mathrm{~min}$ (blue) and I80 min (purple). 
Table II Comparison of the Impurity Levels Formed During Cryomilling of Furosemide

\begin{tabular}{|c|c|c|c|c|c|c|}
\hline \multirow[t]{2}{*}{ Analyte label } & \multirow{2}{*}{$\begin{array}{l}\text { Relative retention } \\
\text { time }\end{array}$} & \multicolumn{5}{|l|}{ Furosemide } \\
\hline & & Crystalline & Cryomilled for $30 \mathrm{~min}$ & $\begin{array}{l}\text { Cryomilled for } 60 \text { min } \\
\text { Amount of analy }\end{array}$ & $\begin{array}{l}\text { Cryomilled for } 120 \mathrm{~min} \\
\text { lyte [\%] }\end{array}$ & Cryomilled for $180 \mathrm{~min}$ \\
\hline imp. I & 0.26 & 0.05 & 0.70 & 1.68 & 4.50 & 5.13 \\
\hline imp. 2 & 0.35 & - & - & 0.06 & 0.06 & 0.07 \\
\hline imp. 3 & 0.76 & - & - & - & - & - \\
\hline imp. 4 & 0.85 & - & - & - & 0.13 & 0.14 \\
\hline imp. 5 & 0.92 & - & - & 0.06 & 0.13 & 0.14 \\
\hline Furosemide & 1.00 & 99.95 & 99.20 & 97.82 & 94.02 & 93.19 \\
\hline imp. 6 & 1.10 & - & - & - & - & - \\
\hline imp. 7 & 1.40 & - & - & 0.06 & 0.17 & 0.21 \\
\hline imp. 8 & 1.42 & - & 0.10 & 0.23 & 0.58 & 0.66 \\
\hline imp. 9 & 1.49 & - & - & - & 0.10 & 0.12 \\
\hline \multirow[t]{3}{*}{ imp. 10} & 1.64 & - & - & 0.09 & 0.31 & 0.34 \\
\hline & & Total impurities & Total impurities & Total impurities & Total impurities & Total impurities \\
\hline & & 0.05 & 0.80 & 2.18 & 5.98 & 6.81 \\
\hline
\end{tabular}

were recorded (Fig. 4, respective chromatograms as indicated by arrows). It can be seen that with increasing milling time, significant increment of the unknown Imp. 1 assigned as the main degradation product was observed, and several minor peaks arise as well. A comparison of impurity profiles of the crystalline furosemide and that cryomilled for different periods of time is given in Table II and Fig. 5. Impurities below $0.05 \%$ are not reported. The quantity of Imp. 1 was closely related to the duration of the cryomilling process, and when the substance was milled for $180 \mathrm{~min}$ it reached a level of $5.13 \%$, while the total content of all impurities formed during this time was $6.81 \%$. To the best of the authors' knowledge, this particular behaviour of furosemide is the first evidence directly showing that cryomilling can be responsible for chemical degradation of the drug. Nevertheless, to investigate this phenomenon in more detail, it is necessary to perform additional studies.

From the literature, it is known that by preparing solid dispersion it is possible to improve physical and chemical stability of amorphous systems (34). One of the methods which can be used to prepare solid dispersion is co-grinding with specially selected excipients such as polyvinylpyrrolidone (PVP) or polysaccharides. Polymer carriers or saccharide derivatives are likely to form amorphous solid solutions. Moreover, they usually have high melting and glass transition points so that their addition to the solid dispersion mixture increases its overall glass transition temperature $\mathrm{T}_{\mathrm{g}}$. Consequently, a considerable decrease in molecular mobility responsible for crystallization tendency and chemical reactivity of amorphous systems can be attained. As believed, the improvement of stability of amorphous mixtures resulted from specific interaction excipient — drug and formation of molecular alloys. Besides, more than 20 years ago, Doherty and Perk revealed that PVP tends to form hydrogen bond with furosemide in solid dispersion, which may account for its stabilization $(35,36)$. Hence, in order to check whether it is possible to prevent chemical degradation of furosemide upon cryomilling, cogrinding has been performed. The mixtures of furosemidePVP and furosemide-inulin (in weight ratios of 1:1 each) were submitted to mechanical treatment at liquid nitrogen conditions. After $60 \mathrm{~min}$ of cryomilling, a complete amorphization of both mixtures was proven by X-ray

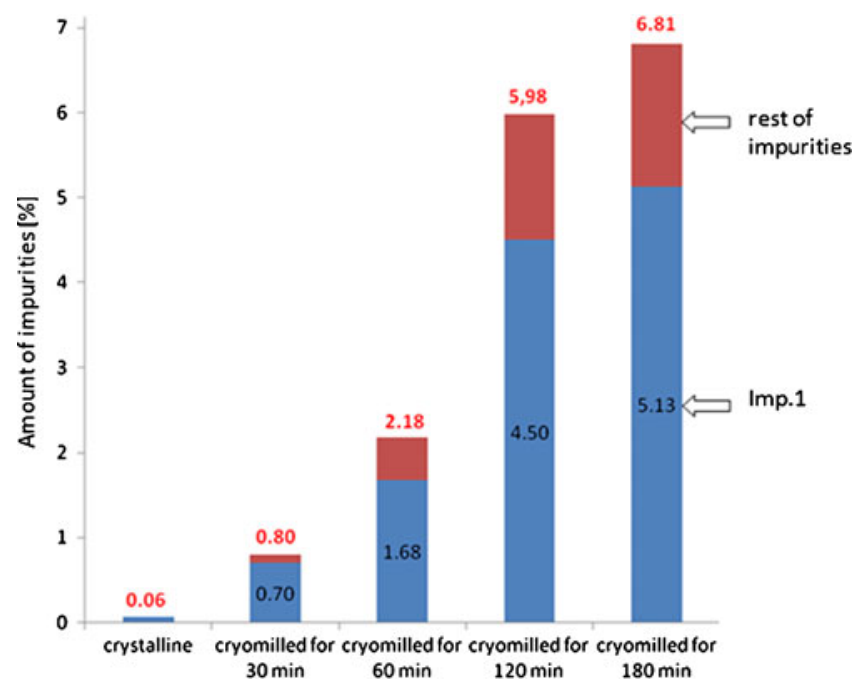

Fig. 5 Comparison of furosemide impurity profiles in relation to the duration of the cryomilling process. 


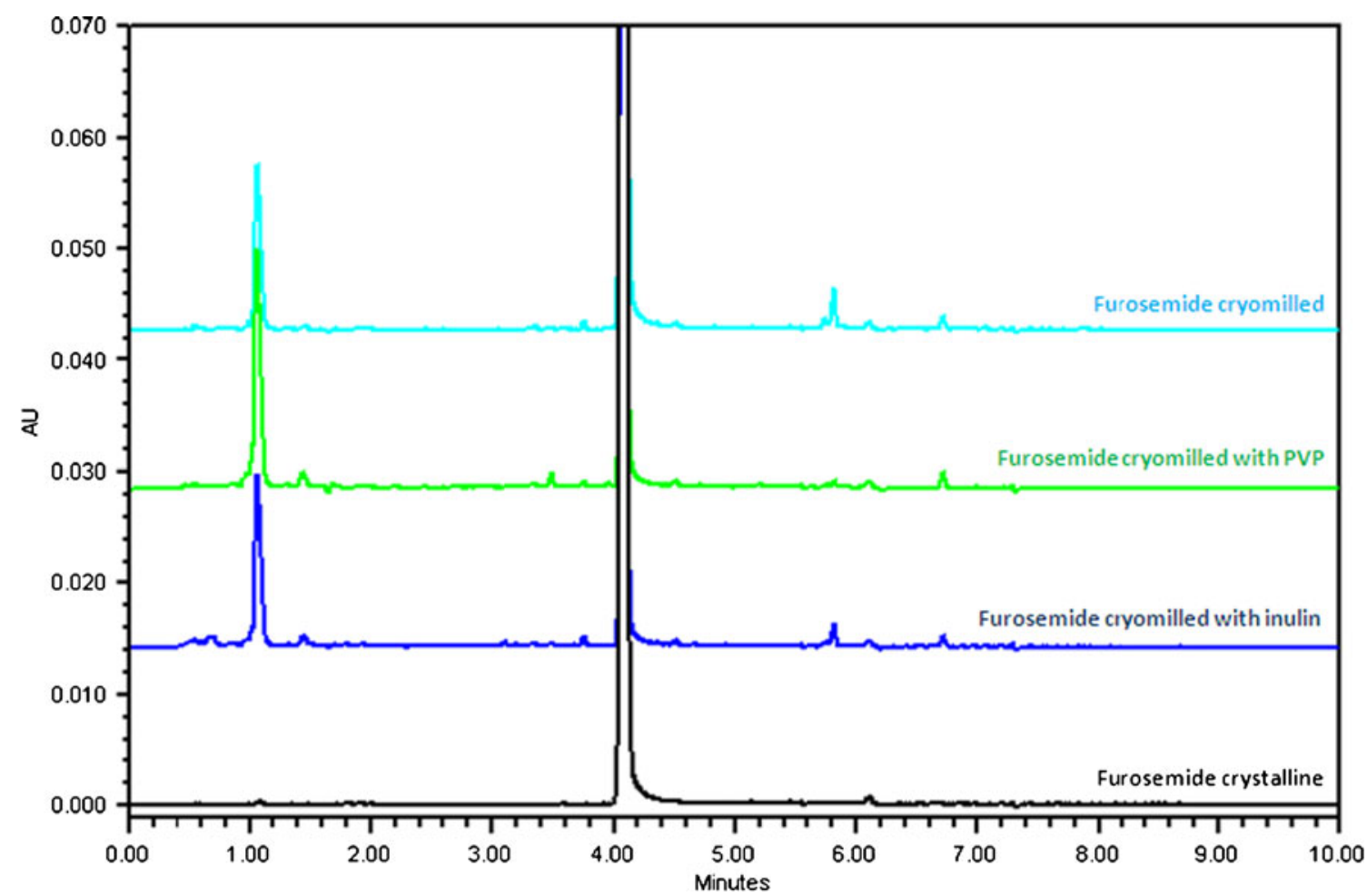

Fig. 6 Overlaid chromatograms of crystalline furosemide (black) and that cryomilled alone for 60 min (blue), with inulin (navy blue) and with PVP (green).

diffractograms (not shown herein). Next, the purity of the outcome materials was tested by UPLG technique. The chromatograms are presented in Fig. 6, and a comparison of the impurities profile is given in Table III (impurities below $0.05 \%$ are not reported). Similarly to furosemide cryomilled alone, in the co-ground furosemide-PVP and furosemide-inulin mixtures, several impurities were detected. Remarkably, a significant increase in the amount of Imp. 1 with relative retention time of 0.26 was reported (respectively, $3.44 \%$ and $5.17 \%$ for furosemide-inulin and furosemide-inulin mixtures). Again, as a consequence of cryogenic mechanical treatment, the purity of the systems is substandard. Based on the above results, we can conclude that grinding of the furosemide with the selected polymer or polysaccharide for a studied weight ratio won't bring chemical stabilization of studied pharmaceutical. The

Table III Comparison of Impurity Profiles of Furosemide Prepared in Different Ways

\begin{tabular}{|c|c|c|c|c|c|}
\hline Analyte label & $\begin{array}{l}\text { Relative retention } \\
\text { time }\end{array}$ & Furosemide crystalline & $\begin{array}{l}\text { Furosemide (cryomilled } \\
\text { for } 60 \mathrm{~min} \text { ) Amount }\end{array}$ & $\begin{array}{l}\text { Furosemide cryomilled } \\
\text { with inulin I: I ratio } \\
\text { nalyte [\%] }\end{array}$ & $\begin{array}{l}\text { Furosemide cryomilled } \\
\text { with PVP I: I ratio }\end{array}$ \\
\hline imp. I & 0.26 & 0.05 & 1.68 & 3.44 & 5.17 \\
\hline imp. 2 & 0.35 & - & 0.06 & 0.19 & 0.26 \\
\hline imp. 3 & 0.76 & - & - & 0.06 & 0.06 \\
\hline imp. 4 & 0.85 & - & - & - & 0.16 \\
\hline imp. 5 & 0.92 & - & 0.06 & 0.12 & 0.07 \\
\hline Furosemide & 1.00 & 99.95 & 97.82 & 95.69 & 93.92 \\
\hline imp. 6 & 1.10 & - & - & 0.05 & 0.08 \\
\hline imp. 7 & 1.40 & - & 0.06 & 0.05 & - \\
\hline imp. 8 & 1.42 & - & 0.23 & 0.25 & 0.08 \\
\hline imp. 9 & 1.49 & - & - & - & - \\
\hline \multirow[t]{3}{*}{ imp. 10} & 1.64 & - & 0.09 & 0.15 & 0.20 \\
\hline & & Total impurities & Total impurities & Total impurities & Total impurities \\
\hline & & 0.05 & 2.18 & 4.31 & 6.08 \\
\hline
\end{tabular}


results of our studies are in a complete opposition to Doherty and Perk's findings, who claimed that no chemical degradation was found in any of their solid solutions (36). However, to prepare amorphous solid dispersions they have chosen a solvent method, in which amorphization mechanism is completely different than that of milling. It is also worth pointing out that they have prepared their solid dispersions in very mild conditions where no degradation occurred $\left(T=50^{\circ} \mathrm{C}\right)$. On the other hand, by carrying out the cryomilling experiment, we have exposed furosemide on extreme conditions and provided at the same time highenergy to the system. In addition, application of mechanical force might lower activation barrier for the chemical reaction to occur. This issue will be discussed later in this paper.

The worsening of chemical stability of furosemide when ground with PVP and inulin as compared to when it was milled on its own is another quite surprising result. Our preliminary measurements indicate that greater chemical instability of cryomilled furosemide-PVP and furosemideinulin solid solutions might be related to the formation of a hydrogen bonding between furosemide and excipient creating the possibility of proton migration across hydrogen bond. Interestingly, application of non-hydrogen bonding matrices improves significantly the chemical stability of cryomilled furosemide, but more detailed studies will be given elsewhere.

To identify the main degradation product formed upon cryomilling (Imp.1), the mass spectrometry and Nuclear Magnetic Resonance techniques have been used. First, the liquid chromatography/mass spectroscopy technique (LC/ MS) was chosen, since it enables not only physical separation of individual impurities, but also can provide valuable information about the molecular weight, structure and/or quantity of a sample. The chromatogram was registered using a PDA detector and a mass spectrometer. The first detection showed the presence of Imp.1 in the eight minute of HPLC analysis (data not shown), but in the mass spectrum the corresponding peak was missing. This could be due to poor ionizability of the unidentified Imp.1 by means of Electrospray Ionization (ESI) technique (see Fig. 7a). Nevertheless, from the recorded mass spectrum we can initially accept the molecular weight of the unknown degradation product formed upon cryomilling as 250.1 daltons. This is confirmed by the presence of $[\mathrm{M}+\mathrm{H}]^{+}$ion of $\mathrm{m} / \mathrm{z} 251.1$ (Fig. 7b). However, to be sure that 250.1 is the exact mass of the unknown Imp. 1, another ionization technique was used. At first, preparative separation of it from the waste fractions was carried out using LG technique. Thus, a fraction containing Imp. 1 was isolated and lyophilized. Next, the Matrix Assisted Laser Desorption Ionization-Time Of Flight Mass Spectrometry (MALDITOF-MS) was used to establish the mass weight of the impurity. This technique was employed mainly owing to its slightly different ionization mechanism. As a MALDI matrix, 2,5-dihydroxybenzoic acid (DHB) was used. In Fig. $7 \mathrm{c}$, a positive-ion MALDI-TOF mass spectrum of the main degradation product formed during cryomilling is presented. The single peak with a $\mathrm{m} / \mathrm{z}$ ratio of 176.9 corresponds to a signal from the DHB matrix with an $\mathrm{Na}^{+}$ adduct. Two very well-shaped signals with $\mathrm{m} / \mathrm{z}$ ratios of 273.0 and 288.3 correspond respectively to the $\mathrm{Na}^{+}$and $\mathrm{K}^{+}$adducts of the unknown impurity of molecular weight $250 \mathrm{u}$. Consequently, the MS analysis has provided reliable information about the most probable molecular weight of the unidentified impurity. However, to avoid any speculation concerning determination of the chemical structure of Imp.1, the ${ }^{1} \mathrm{H}$ NMR spectroscopy was employed. A 400$\mathrm{MHz}{ }^{1} \mathrm{H}$ NMR spectrum of Imp. 1 recorded at $30^{\circ} \mathrm{C}$ covering the range of 0.5 to $9.5 \mathrm{ppm}$ is shown in Fig. 8. As seen in the ${ }^{1} \mathrm{H}$ spectrum, except the peak of the DMSO solvent (a singlet at $2.5 \mathrm{ppm}$, labeled as A), the other three peaks appear at $6.9 \mathrm{ppm}(\mathrm{B}), 7.2 \mathrm{ppm}(\mathrm{C}), 8.3 \mathrm{ppm}(\mathrm{D})$. These ${ }^{1} \mathrm{H}$ chemical shifts were compared with those in the ${ }^{1} \mathrm{H}$ NMR spectrum already known for crystalline furosemide (37). Single and sharp signals at $6.9 \mathrm{ppm}$ and $8.3 \mathrm{ppm}$ were assigned to two aromatic protons, while the single and broad peak at $7.2 \mathrm{ppm}$ was ascribed to sulfonamide $\mathrm{NH}_{2}$. As being distinct from the spectrum of crystalline furosemide, in that of the unknown Imp. 1, there is no response from protons of the furan ring $(6.35 \mathrm{ppm}, 6.4 \mathrm{ppm}$ and $7.6 \mathrm{ppm}$ (37), aromatic -NH proton (8.6 ppm (37)), and that arising from the $\mathrm{CH}_{2}$ group (4.5 ppm (37)). Based on these results, we have concluded that the most probable degradation product formed upon cryomilling of furosemide is 4-chloro-5-sulfamoylanthranilic acid (CSA) with molecular weight equal to $250 \mathrm{u}$. It should also be noted here that an identical ${ }^{1} \mathrm{HNMR}$ spectrum has been reported for a thermal decomposition product of furosemide (38). The chemical structure of CSA is drawn in the inset in Fig. 8b.

The fact that the main degradation product of highimpact cryomilling of furosemide is exactly the same compound as that formed due to thermal decomposition suggests that during extensive mechanical cryomilling, the temperature locally increases in an uncontrollable way so that amorphization occurs due to thermal melting followed by quenching. However, between each cycle, cool-down periods were programmed so that the heat of reaction was repeatedly removed and a low temperature environment was maintained. Still more so, the melting point of furosemide is $>200^{\circ} \mathrm{C}$, while the milling was carried out at a liquid nitrogen temperature $\left(-196^{\circ} \mathrm{C}\right)$. For this reason, local growth of temperature caused by mechanical treatment and resulting in melting with decomposition of furosemide is actually unlikely to happen. Moreover, 
(a)

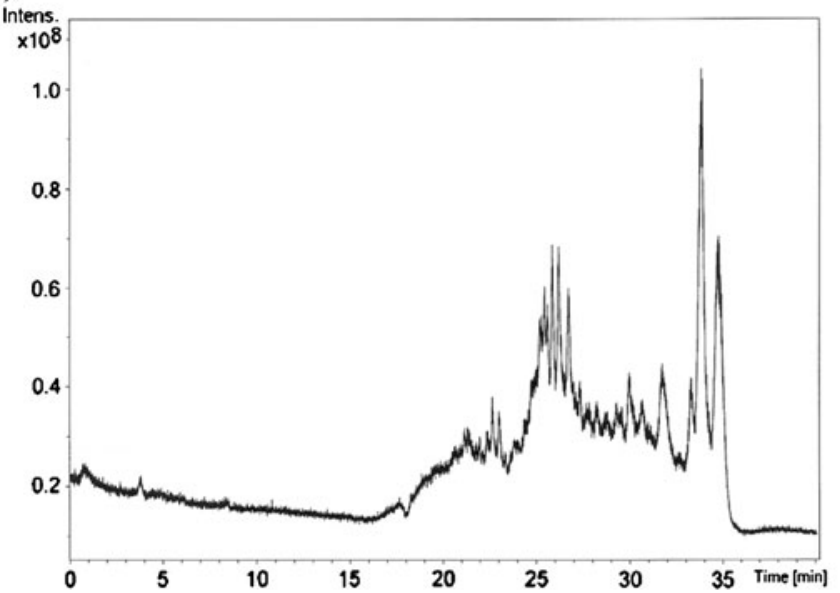

(b)

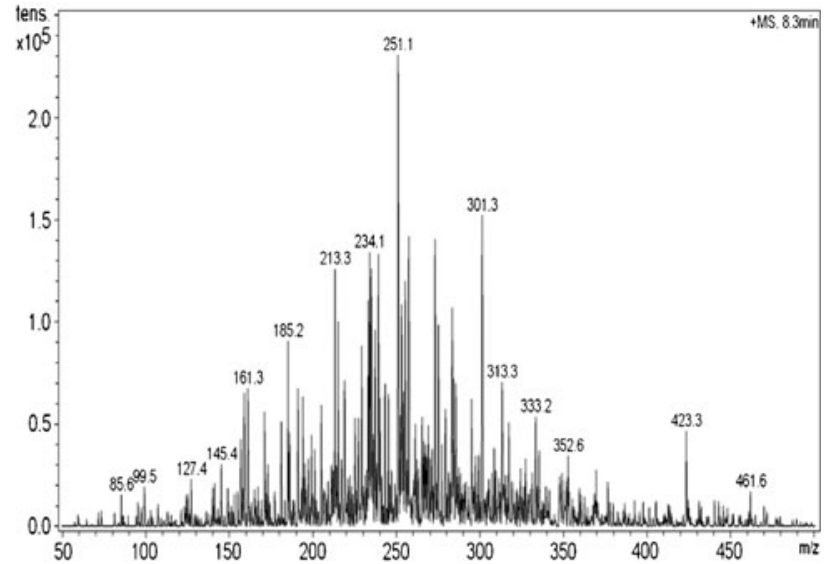

(c)

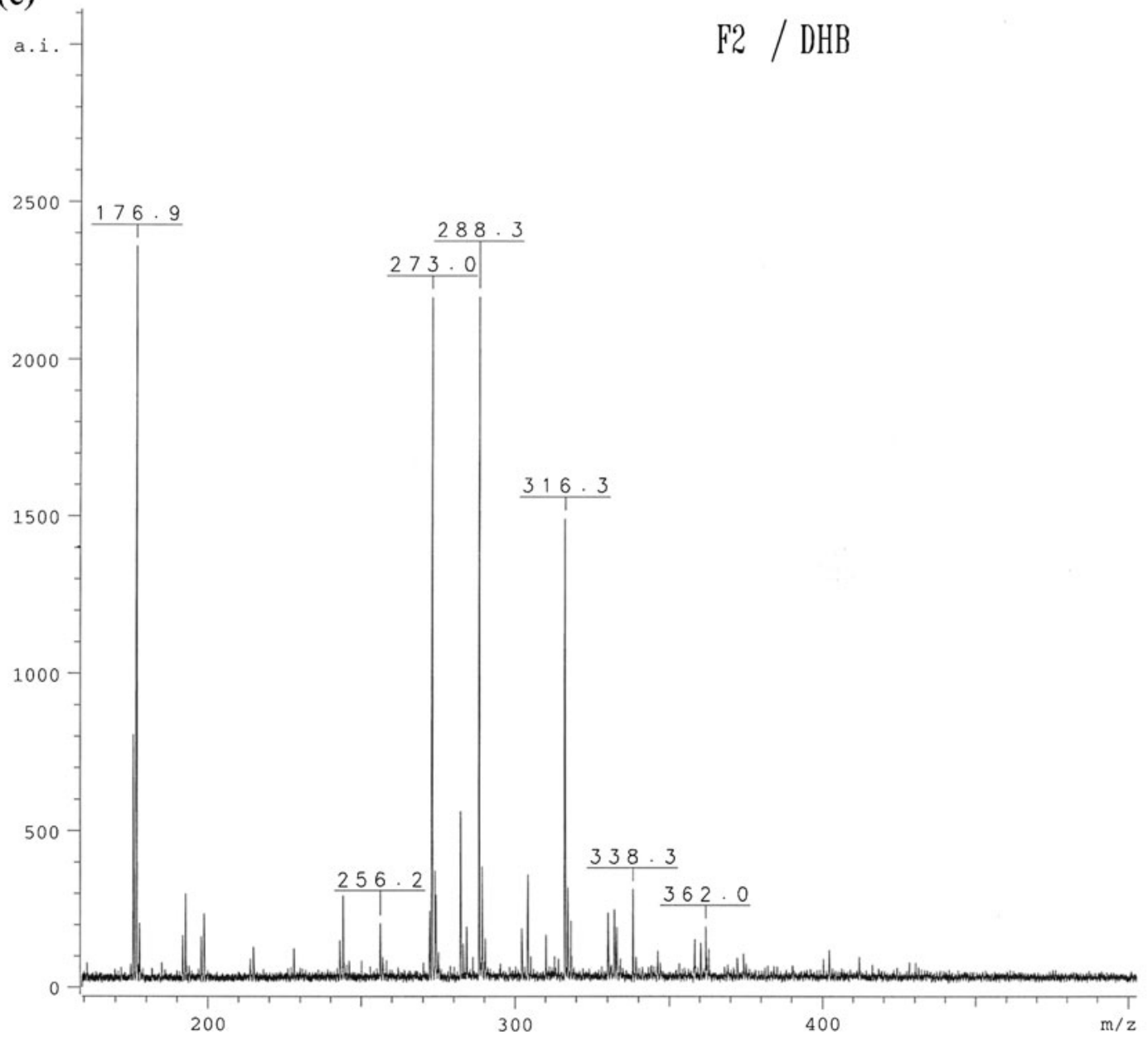

Fig. 7 (a) Positive LC-MS full spectrum of a furosemide sample after cryomilling, (b) positive MS spectrum at the $8^{\text {th }}$ minute of analysis (retention time of the main degradation product formed upon cryomilling), (c) MALDI-TOF MS spectra of the isolated Imp. I (main degradation product formed upon cryomilling).

Decamps et al. have shown that such a scenario even in the case of a material ground at room temperature is fairly impossible $(10,11)$. The absence of mutarotation and carmelization process in cyclic sugars submitted to extensive grinding was proven by the presence of only an $\alpha$-anomeric form in the milled material, while if the melting really had occurred, transformation from $\alpha$ - to $\beta$ - pyranose would have been observed. 
Fig. 8 (a) The 'HNMR spectrum of the main degradation product formed upon cryomilling panel (b) enlarged region from $6.8 \mathrm{ppm}$ to $8.6 \mathrm{ppm}$. (a)

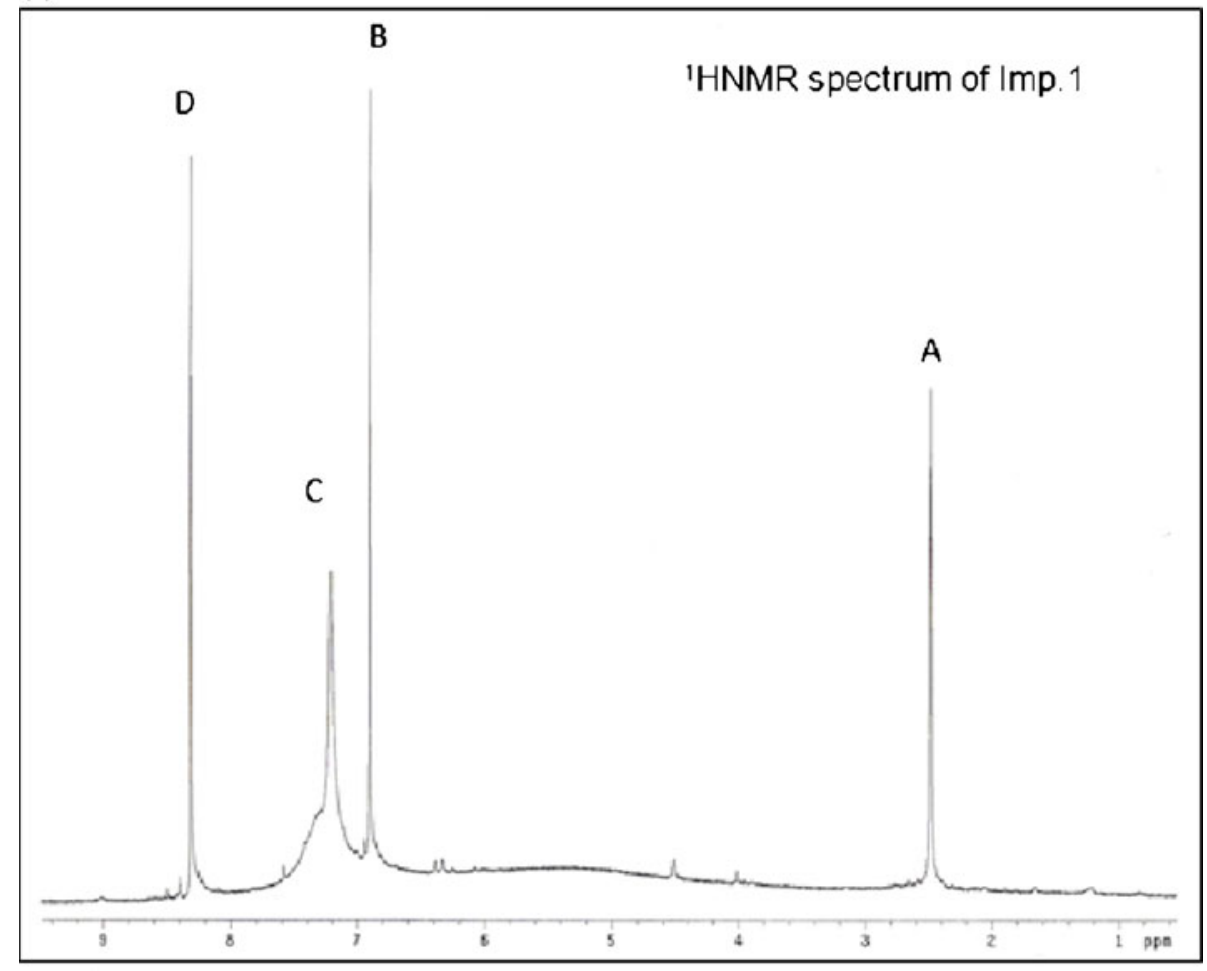

(b)

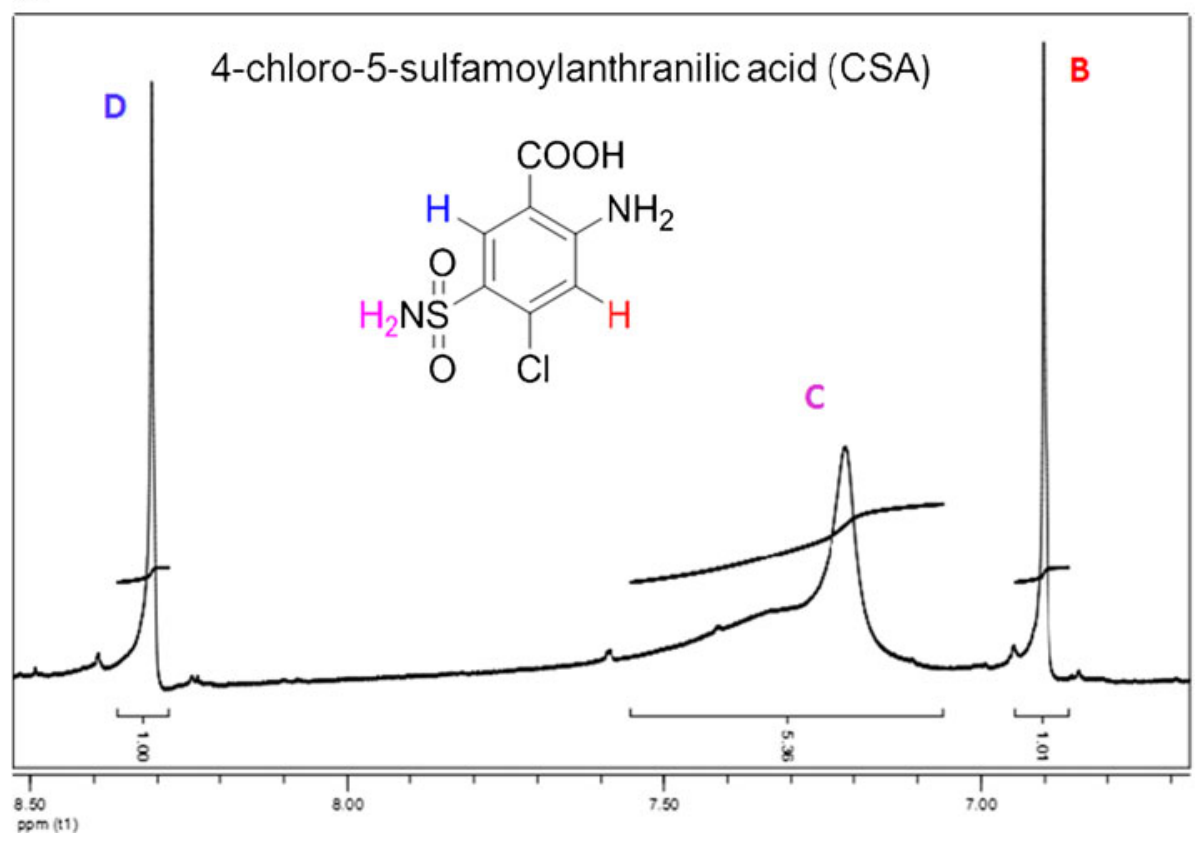

It has been well established that micronized drugs, partially as well as completely amorphous, have an extensive surface area, and for this reason uncontrolled chemical reactions are likely to proceed more quickly as compared to their crystalline counterparts. The rapid growth of chemical reactivity in the amorphous region is often linked to an increasing level of molecular mobility or moisture content (7). It can thus be hypothesized that the increment of Imp. 1 observed upon increasing milling time is related to enhanced chemical reactivity of the amorphous material rather than to any negative effect caused by highimpact milling process itself. To clarify that hypothesis, chemical stability of amorphous furosemide prepared by cryomilling in the solid state and in solution was investigated. 


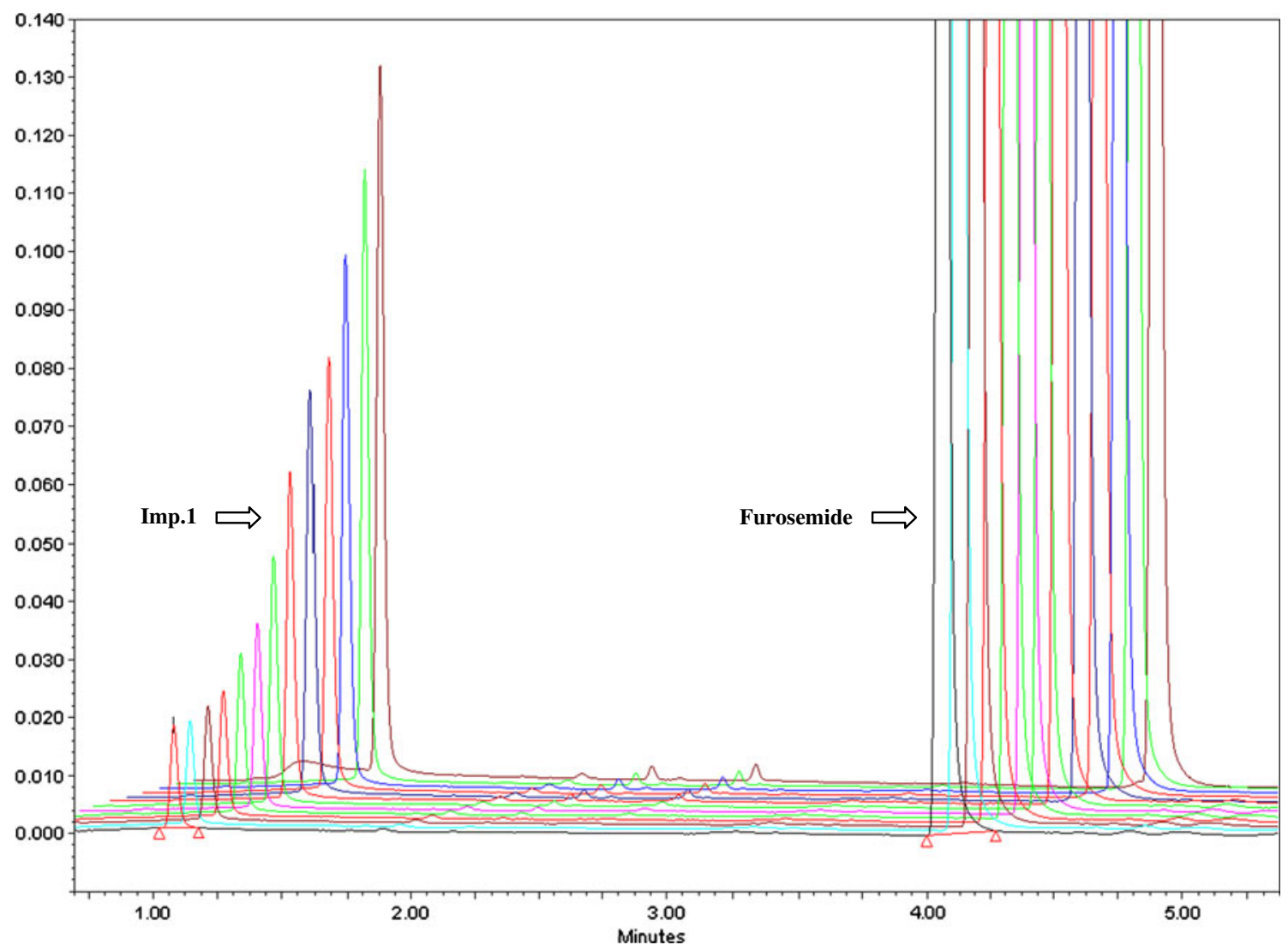

Fig. 9 Increment of Imp. I in acidic environment for cryomilled furosemide (the sample cryomilled for $60 \mathrm{~min}$ ).

The kinetics of the buildup of Imp. 1(CSA) was monitored by UPLC technique. The solid-state degradation study of the cryomilled furosemide extended up to 6 months. As has been found, in a cryomilled powder (one cryomilled for $180 \mathrm{~min}$ ) stored at room temperature for 6 months, an increase in the main degradation product within that period was less than $0.5 \%$ (data not shown herein). Thus, the degradation in the solid state certainly proceeds, but not fast enough to be the reason of a sudden growth of Imp.1 upon cryomilling. It was also found that in organic solvents, such as methanol, the cryomilled drug is quite stable (no significant increment in the impurity level was noticed), while in acidic solutions furosemide underwent acid-catalyzed hydrolysis. In this condition, the linear upturn of Imp. 1 (sample milled $60 \mathrm{~min}$ ) within 12000 min was monitored. The results are shown in Figs. 9 and 10 (in the latter, only the first $4200 \mathrm{~min}$ are shown). As the hydrolysis progressed, a significant growth of the main impurity was observed. This indicates that the cryomilled furosemide is very unstable at lower $\mathrm{pH}$ values, and similarly to crystalline one, CSA is expected to be the main degradation product. It is worth emphasizing that the growth of Imp.1 from $1.68 \%$ to $\sim 6 \%$ required approximately $3600 \mathrm{~min}$ in acidic solution, while the same effect was attained after just 180 min of cryomilling. This implies that chemical degradation induced and proceeding in the highenergy milling has a surprisingly high rate.

For comparison, acid-catalyzed hydrolysis of crystalline furosemide in water solution was carried out. The results in acidic medium are presented in the inset of Fig. 10. We

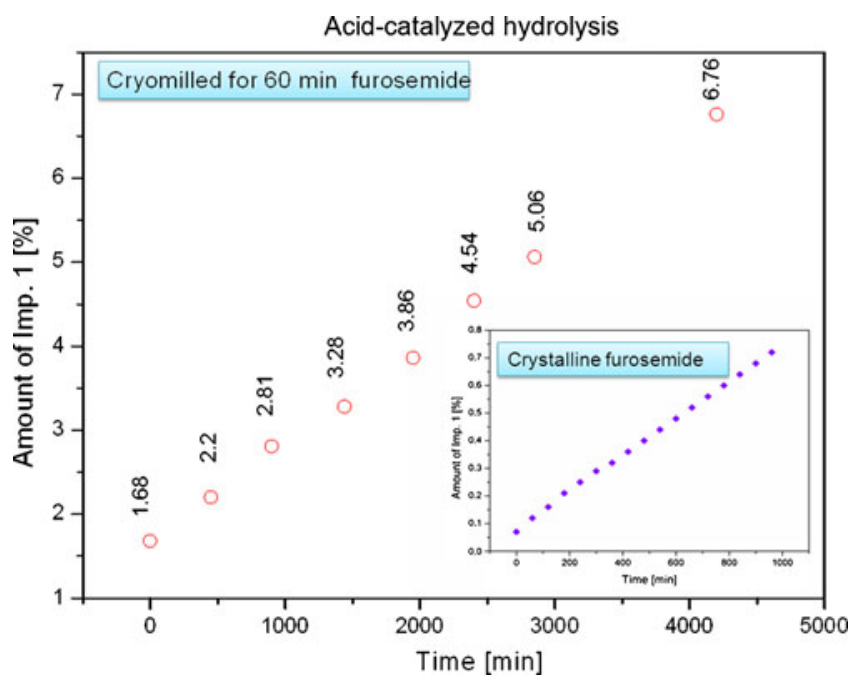

Fig. I0 Buildup of the impurity with relative retention time of 0.26 (Imp. I) in acidic solution. 
have found that within just the first $960 \min (\sim 16 \mathrm{~h})$, the degradation rate of the cryomilled material was roughly about two times higher than that of the crystalline one. As a matter of fact, the cryomilled furosemide undergoes more rapidly acid hydrolysis, and its chemical reactivity is certainly greater than that of the crystalline substance. However, this argument cannot be considered as the dominant reason for the chemical degradation of the cryoground material. Moreover, if degradation of furosemide were only the result of amorphization (i.e. the amorphous form of cryomilled furosemide were so metastable that it decomposed immediately after being formed), after the complete transformation crystalline to amorphous solid, we shouldn't observe any differences in the total impurities amount for all the cryomilled and amorphous samples.

At this point, it should also be noted that up to the present, there are no reports in the pharmaceutical literature clearly showing that cryomilling, as a mechanical process of particle size reduction, might activate and aid chemical degradation of pharmaceuticals. However, the fact that the prolonged high-energy milling can trigger not only structural changes, but also can activate and significantly accelerate chemical process is nothing new. This type of reaction is well-known and recognized as mechanochemical processes. Mechanochemical reactions have very interesting applications, especially in inorganic synthesis $(39,40)$. For example, by ball milling, transition metals such as $\mathrm{Ni}$ or $\mathrm{Co}$ and their oxides can be synthesized. Furthermore, mechanically activated chemical reactions allowed production of semiconductors, alloys or spinels with no need of high temperature conditions required to initiate them otherwise. Originally, chemical processes taking place during mechanical treatment were ascribed to the mechanical energy generated and converted into local heat. However, the resulting products of melting and mechanically initiated reactions might be completely different (40). For this reason, chemical processes occurring in the mill cannot be identified only with an increase in temperature even up to the melting point. Interestingly, in organic chemistry these types of reactions are less likely to proceed and are practically absent. Some signs of chemical transformations caused by mechanical milling were reported for the drug piroxicam (18). In that case, proton transfer (tautomerisation) accompanied solidstate amorphization.

In newly designed high-energy mills the impact generated during the grinding process might be orders of magnitude greater than that achieved in traditional devices. Thus, obviously not only particles sizes can be reduced much faster and easier, but also some chemical reactions which probably would never be accessible by traditional milling can be activated therein. Mechanical milling facilitates chemical reactions due to the randomness of the flattening process. This provides (as grain size decreases) repeatedly new reaction interface. Moreover, at cryogenic temperature, pharmaceutical materials become hard and brittle. Since mechanical treatment of a substance in the mill creates a great amount of stress, such material is obviously more susceptible to any physical and chemical changes. Bearing in mind the above, it is obvious that the milling device must be treated in any circumstances as a chemical reactor where under favourable conditions chemical processes can be mechanically provoked. It is also worth mentioning that in contrast to typical thermochemical reactions, for chemical reactions initiated and promoted by high-impact mechanical treatment, a considerably lower activation energy is required. For example, the activation energy of thermochemical reaction of iron oxide formation was found to be $54 \mathrm{~kJ} / \mathrm{mol}$, while the same reaction caused by mechanical treatment required only $0.7 \mathrm{~kJ} / \mathrm{mol}(40)$.

Rarely have any thermally activated chemical reactions taken place at a very low temperature; if so, it involves mostly inorganic compounds. The rate of thermochemical reaction strongly depends on the temperature and usually increases with increasing temperature. Thus, in the case of cryogenic grinding of furosemide, thermally activated chemical decomposition is simply impossible. On the other hand, the energy required for releasing the mechanochemical reactions is applied to the solid state through mechanical process, not thermally. This would explain why decomposition occurs during high-energy milling even at liquid nitrogen temperature.

Furthermore, the degradation pathway of crystalline and amorphous furosemide in solid state as well as in aqueous solution involves formation of CSA. Conversion of furosemide to CSA proceeds by cleavage of the C-N bond (see Scheme 1). As reported by Beyers et al., the experimentally measured activation energy for thermal decomposition of furosemide is $47.7 \mathrm{kcal} / \mathrm{mol}$, while typically the energy barrier for $\mathrm{C}-\mathrm{N}$ bond cleavage is about $59 \mathrm{kcal} / \mathrm{mol}$ (38). As they speculated in the case of furosemide, the weakening of the $\mathrm{C}-\mathrm{N}$ bond is the consequence of negative inductive effect of the furan ring on the one hand and delocalization

\section{Degradation pathway of cryomilled furosemide}

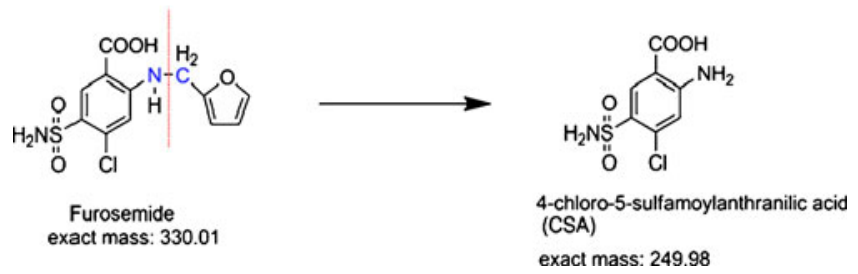

Scheme I Degradation pathway of the cryomilled furosemide. 
of electrons of the aniline nitrogen in the chlorosulfoamyl benzoic acid entity on the other hand (38). It is worth noting that whether one deals with either amorphous or crystalline furosemide in the solid or solution, formation of CSA is always preferable than any other option.

During the high-impact cryogenic grinding, furosemide was prone to decompose to CSA. In other words, the cryogrinding provided enough mechanical energy to initiate chemical reaction. Unfortunately, there is no possible experimental way to verify the amount of mechanical energy that was generated and transferred to the ground sample during mechanical treatment under cryogenic conditions. However, based on some very rudimentary theoretical consideration proposed by Delogu et al. (41), we are able to estimate the mechanical energy dose transferred to a sample, i.e. total energy transfer mechanically transferred to the powder over a definite milling time. Of course, this is only an estimation which does not include the effect of cryogenic temperature upon the milling process. On the other hand, it predicts the potential impact of that mechanical device. In the first step, it is necessary to describe the trajectory of the magnetic rod placed in the grinding vessel and vibrated between two poles of an electromagnet. This trajectory is presented in Scheme 2. In our case, it is rather an easy-toguess path; however, for a cylindrical-shaped traditional ball mill with few balls inside, it might be slightly more complicated (42).

By assuming a purely plastic collision, the impact energy generated per hit can be calculated from the following equation:

$E=\frac{m_{R} v^{2}}{2}$

where $m_{R}$ is the mass of the magnetic rod and $v$ is its velocity. The latter can be calculated knowing specific milling configuration and size of the vessel. The impact energy was found to be $E=1.5 \mathrm{~mJ} /$ hit. From impact energy $\mathrm{E}$ and frequency $\mathrm{N}$ generated per hit, the milling intensity can be determined as (41)

$I=E \cdot \mathcal{N}$

This leads to $I=22 \mathrm{~mW}$. The total energy transferred to the powder, known also as the specific milling dose, is given by (41)

$D_{m}=\frac{E \cdot \mathcal{N} \cdot t}{m_{p}}$

where $m_{p}$ is the mass of the powder and $t$ refers to the total milling time. Assuming the total mass of the powder as $1 \mathrm{~g}$, our consideration leads to the following values: 6.5, 12.5, and $18.7 \mathrm{kcal} / \mathrm{mol}$ for 60,120 and $180 \mathrm{~min}$ of grinding,
Scheme 2 Typical vessel used for high-impact cryogenic grinding.

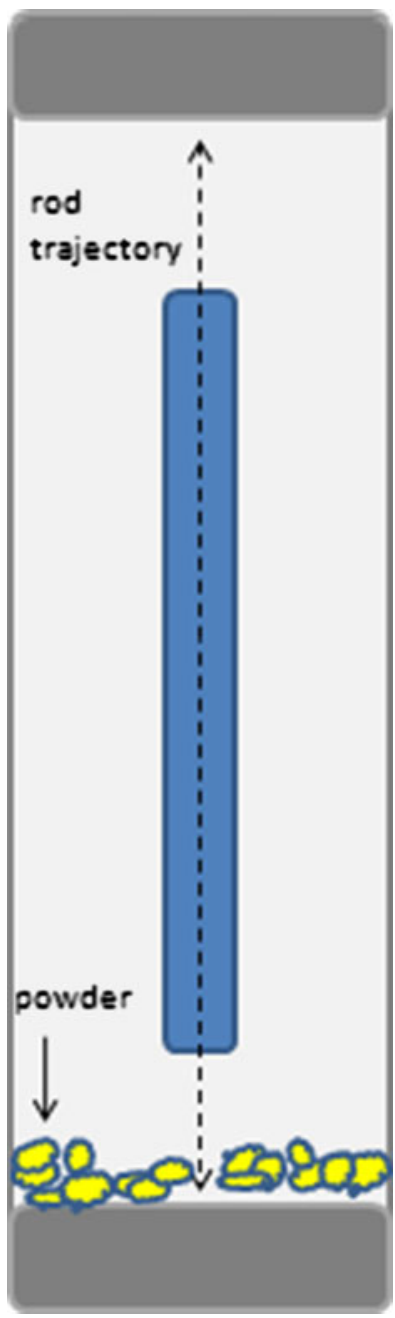

respectively These values are obviously not high enough to cause decomposition of the drug upon milling, especially because the cryogenic temperature effect was not taken into account. However, one should be aware that during milling the collisions are more likely heterogeneous rather than homogenous. Thus, the energy transfer to each particle wouldn't be the same. Some of them would receive it more, while others less, and only those entities which received enough energy to overcome activation barrier would be decomposed. As revealed by UPLC studies, just $2.18 \%$, $5.98 \%$ and $6.81 \%$ out of $1 \mathrm{~g}$ of furosemide sample decompose after, respectively, 60, 120 and $180 \mathrm{~min}$ of milling. If the specific milling dose is calculated for only such amounts of the powder (according to their total milling time), we obtain that in each case the energy transferred to the samples exceeds more than $200 \mathrm{kcal} / \mathrm{mol}$. These theoretical estimations indicate that the milling is able to generate enough energy to overcome the energy barrier and initiate decomposition of furosemide. However, experimental values of total energy transferred to the sample would certainly be lower. We suppose that as the particle 
size decreases and the transformation of crystalline drug to amorphous one is attained, mechanically activated degradation of furosemide would speed up due to increased surface area of the cryoground material and its enhanced chemical reactivity.

Finally, it should be also noted that the UPLC analysis of furosemide ball-milled at room temperature for 1440 min revealed total impurity level less than $0.6 \%$ (data not shown in this paper). Accordingly, we think that there must be a relationship between full amorphization of furosemide and acceleration of its degradation. Since we are not able to completely amorphize furosemide in the ball-mill, just small amounts of impurities were found in that sample. Only by performing the cryogenic experiment we are able to monitor the degradation of furosemide, because only this highimpact device is able to provide enough mechanical energy for full amorphization of the material. We also conjecture that in a region very close to complete amorphization and just above that point, this process proceeds at a maximum rate. In our opinion, the fact that the decomposition proceeds faster between time intervals of 30-60 $\mathrm{min}$ and 60-120 $\mathrm{min}$ and slower between 120 and $180 \mathrm{~min}$ (see Fig. 5 or Table I) indicates that this reaction has slowly reached a saturation point, and longer mechanical treatment won't change anything.

\section{CONCLUSIONS}

Cryomilling of a crystalline powder is becoming a very popular way of micronization as well as amorphization. Since the milling takes place at a liquid nitrogen temperature, it is possible to effectively reduce particle size within a relatively shorter time and, as believed, to prevent local heating. Mechanical milling of pharmaceuticals offers a lot of advantages, especially in the context of solubility and bioavailability improvement. The high-impact cryomilling enables production of completely amorphous materials that otherwise could not be obtained during the room temperature ball-milling. However, current studies revealed that in some circumstances it can activate and accelerate not only structural changes (solid state amorphization) but also chemical decomposition of drug. For this reason, more attention should be paid to controlling the purity of the starting cryoground materials.

The examined herein drug substance, furosemide, was found to be physically and chemically unstable after extensive cryomilling. The chemical decomposition of the mother material was found to be directly correlated with the duration of the cryomilling process. Degradation of furosemide that proceeds upon cryogenic grinding is most probably initiated in the vicinity of the amorphization region, since amorphous materials are known for their greater chemical reactivity, and in opposition to crystalline counterparts, they are more susceptible to any unwanted chemical changes. Acidcatalyzed hydrolysis of the cryoground amorphous sample proceeds at an almost twice greater pace than that of the crystalline drug. It is a clear sign of intensified chemical reactivity of the amorphous material in solution. During longterm storage of the cryomilled material in the solid state at ambient conditions, the degradation proceeds, albeit much slower. However, most surprising is its acceleration provoked by the high-impact mechanical treatment. Only after $180 \mathrm{~min}$ of cryomilling, the increment of Imp. 1 (CSA) reached the same value as that found in the acid solution after dozen of hours. It is worthwhile to note that in a low $\mathrm{pH}$ medium the rate of hydrolysis is reported to be the highest. This attracts our attention to an enormous potential of the high-impact device, creating a favourable environment for various reactions activated mechanically to arise, with no need of any solvents.

The degradation pathway of furosemide in the solid state and solution involves formation of the same product, CSA. The lower activation barrier required for such transformation is probably the direct consequence of weakening of the C-N bond and can be overcome by providing enough mechanical energy during the crashing process. Mechanical milling, due to randomness of each collision provides repeatedly new reaction interface and facilitates decomposition of the compound. Since chemical reaction activated by mechanical treatment does not need a thermal factor to begin, decomposition of furosemide is likely to proceed even at a liquid nitrogen temperature. The scenario which assumes local heating in the milling device, causing melting and thermal decomposition of furosemide, is less likely to happen, especially because of the temperature at which the milling is performed.

\section{ACKNOWLEDGMENTS \& DISCLOSURES}

The authors are deeply thankful for the financial support of their research within the framework of the project entitled "From Study of Molecular Dynamics in Amorphous Medicines at Ambient and Elevated Pressure to Novel Applications in Pharmacy" (Contract No. TEAM/2008-1/6), which is operated within the Foundation for Polish Science Team Programme co-financed by the EU European Regional Development Fund. The authors are deeply grateful to Professor Ryszard Piękoś from Department of Inorganic Chemistry, Medical University of Gdansk, Poland, for helpful discussions and valuable advice.

Open Access This article is distributed under the terms of the Creative Commons Attribution Noncommercial License which permits any noncommercial use, distribution, and reproduction in any medium, provided the original author(s) and source are credited. 


\section{REFERENCES}

1. Amidon GL, Lennernäs H, Shah VP, Crison JR. A theoretical basis for a biopharmaceutic drug classification: the correlation of in vitro drug product dissolution and in vivo bioavailability. Pharm Res. 1995;12:413-20.

2. Chaumeil JC. Micronisation: a method of improving the bioavailability of poorlysolubledrugs. Methods Find Exp Clin Pharmacol. 1998;20:211-5.

3. Sheth AR, Bates S, Muller FX, Grant DJW. Polymorphism in piroxicam. Cryst Growth Des. 2004;4:1091-8.

4. Chieng N, Zujovic Z, Bowmaker G, Rades T, Saville D. Effect of milling conditions on the solid-state conversion of ranitidine hydrochloride form 1. Int J Pharm. 2006;327:36-44.

5. Murdande SB, Pikal MJ, Shanker RM, Bogner RH. Solubility advantage of amorphous pharmaceuticals: II. Application of quantitative thermodynamic relationships for prediction of solubility enhancement in structurally diverse insoluble pharmaceuticals. Pharm Res. 2010; doi:10.1007/s1 1095-010-0269-5.

6. Yoshioka M, Hancock BC, Zografi G. Crystallization of indomethacin from the amorphous state below and above its glass transition temperature. J Pharm Sci. 1994;83:1700-5.

7. Shamblin SL, Hancock BC, Pikal MJ. Coupling between chemical reactivity and structural relaxation in pharmaceutical glasses. Pharm Res. 2006;23:2254-68.

8. Di L-M, Loeff PI, Bakker H. Atomic disorder in $\mathrm{Nb}_{3} \mathrm{Sn}$ during heavy mechanical impact. J Less-Common Met. 1991;168:183-93.

9. Desprez S, Decamps M. Transformation of glassy indomethacin induced by ball-milling. J Non-Cryst Solids. 2006;353:4480-5.

10. Willart JF, Caron V, Lefort R, Dandède F, Prèvost D, Decamps M. Athermal character of the solid state amorphization of lactose induced by ball milling. Solid State Commun. 2004;132:693-6.

11. Decamps M, Willart JF, Dudognon E, Caron V. Transformation of pharmaceutical compounds upon milling and comilling: the role of Tg. J Pharm Sci. 2007;96:1398-407.

12. Fukuoka E, Markita M, Yamamura S. Some physicochemical properties of glassy indomethacin. Chem Pharm Bull. 1986;34:4314-21.

13. Crowley KJ, Zografi G. Cryogenic grinding of indomethacin polymorphs and solvates: assessment of amorphous phase formation and amorphous phase physical stability. J Pharm Sci. 2002;91:492507.

14. Lam NQ, Okamoto PR, Li M. Disorder-induced amorphization. J Nucl Mat. 1997;251:89-97.

15. Fech HJ. Defect-induced melting and solid-state amorphization. Nature. 1992;356:133-5.

16. Decamps M, Willart JF, Aumelas A. The Glass Transition of Driven Molecular Materials. Complex Systems 5th International Workshop on Complex Systems. 2008;53:61.

17. Shakhtshneider TP, Danède F, Capet F, Willart JF, Decamps M, Myz SA, et al. Grinding of drugs with pharmaceutical excipients at cryogenic temperatures, Part 1. J Therm Anal Calorim. 2007;89:699-707.

18. Sheth AR, Lubach JW, Munson EJ, Muller FX, Grant DJW. Mechanochromism of piroxicam accompanied by intermolecular proton transfer probed by spectroscopic methods and solid-phase changes. J Am Chem Soc. 2005;127:6641-51.

19. Greaser KA, Strachan CJ, Patterson JE, Gordon KC, Rades T. Physicochemical properties and stability of two differently prepared amorphous forms of simvastatin. Cryst Growth Des. 2008;8:128-35.

20. www.drugbank.ca.
21. Ogata H, Kawatsu Y, Maruyama Y, Machida K, Haga T. Bioavailability and diuretic effect of furosemide during long-term treatment of chronic respiratory failure. Eur J Clin Pharm. 1985;28:53-9.

22. Bundgaard H, Norgaard T, Nielsen NM. Photodegradation and hydrolysis of furosemide and furosemide esters in aqueous solutions. Int J Pharm. 1988;2:217-24.

23. Valladao DMS, De Oliveira LCS, Zuanon Netto J, Ionashiro M. Thermal decomposition of some diuretic agents. J Therm Anal. 1996;46:1291-9.

24. Amin Kreaz RM, Abu-Eida EY, Eros I, Kata M. Freeze-dried complexes of furosemide with $\beta$-cyclodextrin dervatives. J Incl Phenom Macrocyclic Chem. 1999;34:39-48.

25. Ghanekar AG, Gupta VG, Gibbs Jr CW. Stability of furosemide in aqueous systems. J Pharm Sci. 1978;67:808-11.

26. Iannuccelli V, Coppi G, Leo E, Fontana F, Bernabei MT. PVP solid dispersion for the controlled pelease of furosemide from a floating multiple-unit system. Drug Dev Ind Pharm. 2000;26:595-603.

27. Shin S-C, Oh I-J, Lee Y-B, Choi H-K, Choi J-S. Enhanced dissolution of furosemide by coprecipitating or cogrinding with crospovidone. Int J Pharm. 1998;175:17-24.

28. Villiers MW, Tiedt RL. An analysis of fine grinding and aggregation of poorly soluble drug powders in a vibrating ball mill. Pharmazie. 1996;51:564-7.

29. Kaminski K, Adrjanowicz K, Wojnarowska K, Grzybowska K, Hawelek L, Paluch M, et al. Molecular dynamics of the cryomilled base and hydrochloride Ziprasidones by means of dielectric spectroscopy. J Pharm Sci. 2011; doi:10.1002/jps.22479.

30. Cruz JE, Yakatan GJ. Kinetics and mechanism of hydrolysis of furosemide. Int J Pharm. 1979;2:275-81.

31. Al-Omar IA, Al-Ashban RM, Shah AH. Toxicity studies on 4chloro-5-sulfamoylanthranilic acid the degradation product of a loop diuretic furosemide. Res J Pharmac. 2009;3:63-77.

32. Moore DE, Sithipitak V. Photolytic degradation of frusemide. J Pharm Pharmacol. 1983;35:489-93.

33. Adrjanowicz K, Grzybowska K, Kaminski K, Hawelek L, Paluch M, Zakowiecki D. Complex studies on physical and chemical stability in liquid and glassy states of Telmisartan (TEL). Solubility advantages given by cryomilled and quenched material. Phil. Mag. in press.

34. Bühler V. Polyvinylpyrrolidone excipients for pharmaceuticals. Berlin: Springer-Verlag; 2005.

35. Doherty C, York P. Evidence for solid- and liquid-state interactions in a furosemide-polyvinylpyrrolidone solid dispersion. J Pharm Sci. 1987;76:731-7.

36. Doherty C, York P. Accelerated stability of an x-ray amorphous furosemide-polyvinylpyrrolidone solid dispersion. Drug Dev Ind Pharm. 1989;15:1969-87.

37. Spamer E, Muller DG, Wessels PL, Venter JP. Characterization of the complexes of furosemide with 2-hydroxypropyl- $\beta$-cyclodextrin and sulfobutyl ether-7- $\beta$-cyclodextrin. Eur J Pharm Sci. 2002; 16:247-53.

38. Beyers H, Malan SF, van der Waat JG, de Villiers MM. Structure-solubility relationship and thermal decomposition of furosemide. Drug Dev Ind Pharm. 2000;36(10):1077-83.

39. McCormick PG, Froes FH. The fundamentals of mechanochemical processing. J Miner Met Mater Soc. 1998;50(11):61-5.

40. Heinickie G. Tribichemistry. Berlin: Akademic-Verlag; 1984.

41. Delogu F, Schiffini L, Cocco G. The invariant laws of the amorphization processes by mechanical alloying. I Experimental findings. Phil Mag A. 2001;81(8):1917-37.

42. Andrade-Gamboa J, Gennari FC, Arneodo Larochette P, Neyertz C, Ahlers M, Pelegrina JL. Stability of Cu-Zn phases under low energy ball milling. Mat Sci Eng A. 2007;447:324-31. 